\title{
Rodent General Anesthesia Suitable for Measurement of Experimental Invasive Hemodynamics
}

\author{
Filip Konecny
}

\section{ABSTRACT}

In cases of experimentally performed invasive rodent cardiovascular measurements, selected general anesthesia for a non-recovery procedure and its proper pain control plays a fundamental role in obtaining good data recordings. Rodent anesthesia is challenging for several reasons including high metabolic rate with elevated possibility of hypothermia and hypoglycemia during the procedure, large body surface area to adjust drug medication and anticipate drug clearance. In this review article, suitable analgesia, and anesthesia to collect rodent hemodynamics is discussed with examples of commonly used methods and anesthetic combinations to assess rodent hemodynamics. In case of injectable anesthesia, hemodynamic parameters should be measured when HR and mean arterial pressure (MAP) becomes stable. If re-injection is necessary, re-evaluation of HR and MAP is crucial for data integrity. Likewise, to safeguard data quality, longitudinal collection of HRs, HR variability, MAP and body temperature should be provided. For this reason, creation of a rodent hemodynamic anesthesia protocol might be necessary. In many cases, to refine surgical anesthetic protocol suitable for hemodynamic study, pilot experiments might be required to find the correct dose, and to probe for adequacy and duration of anesthesia, anticipating technical and procedural problems. Additionally, ensuring repeatability of the hemodynamic exam, selected experimental anesthetics should not be extensively metabolized. If metabolized, the effects on central and peripheral hemodynamics (HR, pre, afterload and contractility) should be well-known and documented.

Keywords: anesthesia monitoring, controlled mechanical ventilation, inhalation anesthesia, injectable, rodent general anesthesia.

\section{Desirable Quality of ANALGESIA AND ANESTHESIA TO COLLECT RODENT HEMODYNAMICS - THE ANESTHETIC TRIANGLE}

As collection of cardiovascular hemodynamic parameters using an invasive catheterization requires surgical procedure, ensuring stability of general anesthesia (immobilization and loss of sensations) with an appropriate analgesia, accompanied by the muscle relaxation is the key to collection of an excellent hemodynamics, please see the basic anesthetic triangle at Fig 1. In many cases, stable anesthesia is a balancing act between preservation of HR and BP near the physiological values with proper immobilization, muscle relaxation and analgesia. Players of this balancing act should be selected based on its effects they may have on hemodynamics prior to the rodent surgery. Anesthetic potency is a surrogate measure of the anesthetic effects. Major measure of this effect is minimal alveolar concentration (MAC) and the equivalent of the EC 50 for intravenous drugs. MAC that has been shown to be a good surrogate, especially in spinal, but less in cortical response
Published Online: August 23, 2021

ISSN: 2684-5199

DOI: $10.24018 /$ ejbio.2021.2.4.259

Filip Konecny*

Department of Surgery, Division of

Plastic Surgery, McMaster University, Hamilton, ON, Canada.

(e-mail: konecny@mcmaster.ca)

*Corresponding Author
[1]. In extension, due to an improved use of peripheral muscle relaxants (one of the corners of the triangle at Fig. 1), observation of other reflexes has to be intensified using measurements and observations of HR, arterial pressure, the rate and volume of ventilation, the diameter and reactivity of pupils to light. In veterinary medicine, measures of HR and $\mathrm{BP}$ are considered the mainstay of anesthesia monitoring along with an observation of quality of ventilation, which altogether would give out indices that could serve as guide, especially when it comes to rodents. MAC as a "hard index" of anesthesia potency in rodents, being a surrogate, might be an important step forward in administering rodent anesthesia, however years of experience with doses and its combination along with a developed common observational sense, could be as important. Additionally, an empirically tested anesthetic doses and its selected combinations, using both an acute dose testing and longitudinal telemetry methods, could serve as a good catalyst, marrying an adequate anesthesia while ensuring an excellent cardiovascular data collection.

Basic pharmacokinetics (what does an organism do with the drug) have uncovered that no two anesthetics act on the 
same target; and they all have their individual ranges of effects. Additionally, that single anesthetic suppresses proteins by more than one action, hence can involve several different molecular targets.

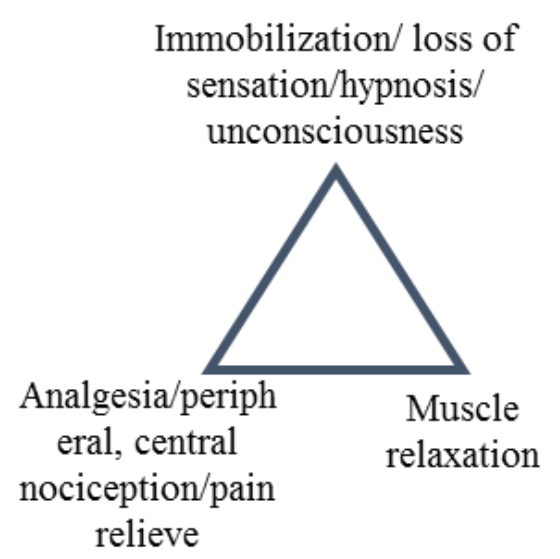

Fig. 1. Basic anesthetic triangle; necessities of balancing surgical anesthesia prior to hemodynamic recording.

Anesthetics possess relative strengths (quantitative) with suppression as well as potentiation, which may occur (qualitatively) [2], [3]. More about the physical and chemical interaction of the anesthetics can be found in monographies discussing e.g., solution theories and Meyer-Overton rule (strong correlation between anesthetic potency and solubility in oil) performed throughout decades of research. With development of new methods and techniques in recent times, activity of ion channels in the membrane of nerve cells, reacting on general anesthetics, were explored in more detail. The inhibitory ligand-gated ion channels effect of barbiturates, benzodiazepines, anesthetic steroids, volatile gases such as isoflurane and sevoflurane, hypnotic etomidate and propofol, were shown to increase the activity of $\gamma$ aminobutyric acid (GABA A) receptors and its receptor subtypes [4], whereas ketamine and nitrous oxide were exceptions, not modulating the activity of GABA A receptors, but acting through $\mathrm{N}$-methyl-D-aspartate (NMDA) receptor, class of glutamate gated channels receptor [5]. It is beyond the scope of this review to detail all receptor mediated anesthetic interactions. Interested readers can find more info in monographies by [3], [4], [6].

Another corner of the anesthetic triangle is occupied by the analgesia. Using premedication by tranquillizers and analgesics in rodents, is generally aimed to ease the apprehension and to encourage stress-free induction. The preemptive analgesia is always recommended in case of an invasive procedures, where it serves to a painless induction to a full surgical anesthesia as opposed to less-invasive cardiovascular imaging techniques, such as echocardiography or micro-CT imaging, where it might serve to induce constant immobility to avoid movement artifacts. In case of transthoracic echocardiography (TTE) or micro-CT imaging pain might be monitored however, in many cases during a non-invasive hemodynamic imaging rodent can be trained to be fully conscious during imaging by using different restraining techniques thus the pre-emptive or periprocedural analgesia is not required [7], [8]. In the majority of cases, pain management is directly related to the level of invasiveness with greater scrutiny placed on the surgeon. Lastly and particularly in a research setting, researchers have to also use good judgment to be able to compare hemodynamics (non-invasive vs. invasive technique). In cases of data comparison using measurement techniques, both procedures should complement each other (e.g., TTE of the LV outflow with perivascular blood flow/ $\mathrm{CO})$. Frequently, in post imaging data review, accompanied analgesia and selected anesthesia needs to correspond to successfully appraise e.g., the cardiac load dependent parameters, as both should be completed under similar breath $( \pm 5 \%)$, and heart rates $( \pm 5 \%)$, accompanied by similar body temperature, alongside with records of drug injection and reinjections, or levels of volatile anesthesia during the exam, etc. Critical is to make good notes accompanying the imaging test if hemodynamics is to be scrutinized. Lastly, one has to pay attention to general anesthetics, as they can also modulate changes in sympathetic nerve activity and in extension the effects on the central or peripheral nervous system with the final effect of modulation of BP [9], [10]. For this reason, non-invasive imaging should be also accompanied with a reliable collection of ECG, heart, or breath rate and notes about body temperature or drug reinjections.

\section{COMmonly USED ANESTHETIC COMBINATIONS TO ASSESS RODENT HEMODYNAMICS}

To perform an invasive surgical procedure with the end goal of an intravascular access, multiple anesthesia/analgesia combinations can be utilized. Experimental procedures in rodents necessitate pre-emptive analgesia followed by anesthesia induction that might be performed by 1) using inhalation chamber induction switching to face mask ventilation (as means of non-invasive ventilation type); all supplied by mixture of gaseous anesthesia without rodent being 2) invasively orotracheally intubated by rodent-specific ET (endotracheal tube), with an addition of controlled mechanical ventilation (CMV). These 2 types of volatile gas anesthetic delivery (invasive and non-invasive) provide means of inhalation anesthesia. Both can be further combined with an injectable anesthesia/analgesia. The third common choice of anesthesia during an invasive rodent surgical protocol consists of a pre-emptive analgesia followed by an injectable anesthesia, without intubation or delivery of inhalation gas. It is the least recommended type of anesthesia when performing an acute cardiovascular microsurgery to assess rodent hemodynamic parameters. Using an injectable anesthesia during hemodynamic experimentation has its limitations, especially in cases when a rodent is slowly regaining consciousness and (or) during anesthetic reinjections. In both cases, experimental notes in the protocol have to reflect stage(s) of anesthesia for its later data analysis and also for imaging comparisons, as mentioned in the introduction. Most common reasons for not using gaseous anesthesia are unavailability, unfamiliarity, or unaffordability of e.g., volatile gas precision vaporizer, rodent mechanical ventilator and its circuitry, medical oxygen, or gas scavenging and its evacuation. 


\section{Stages of Rodent General ANESTHesia}

As there are currently recognized total of IV stages of general anesthesia (stage I: voluntary movement; stage II: delirium stage or involuntary movement; stage III: surgical anesthesia; stage IV: extreme central nervous system depression), an invasive vascular catheterization requires stage III, plane III; please see Table I below for plane assessment at stage III; all based on the classifications by Guedel [11] and [12].

TABLE I: Planes of ANESTHESIA AT StAGE III BASED ON GUEDEL'S

\begin{tabular}{|c|c|}
\hline \multicolumn{2}{|r|}{ ClassifiCATION } \\
\hline $\begin{array}{l}\text { Anesthesia } \\
\text { Planes }\end{array}$ & $\begin{array}{c}\text { Description of Anesthesia Plane at the } \\
\text { Stage III }\end{array}$ \\
\hline Plane I Light & $\begin{array}{l}\text { The animal has irregular pulse with normal } \\
\text { MAP, increased depth and breath rate with } \\
\text { irregular breathing pattern. Pupil reacts to light, } \\
\text { and the animal has an involuntary eye movement. } \\
\text { Some reflexes are lost, with loss of muscle tone }\end{array}$ \\
\hline $\begin{array}{l}\text { Plane } \\
\text { Medium }\end{array}$ & $\begin{array}{l}\text { The animal has an irregular pulse which is } \\
\text { getting faster, MAP increases. Respiration is still } \\
\text { irregular, but shallower. Pupils still react to light. } \\
\text { The toe pinch reflex may be still present. }\end{array}$ \\
\hline $\begin{array}{l}\text { Plane } \\
\text { Deep }\end{array}$ & $\begin{array}{l}\text { The animal has a steady and slow pulse. MAP } \\
\text { value stabilizes. Breath rate becomes regular but } \\
\text { decreased, animals show steady inhalation and } \\
\text { exhalation periods. Respiratory depth is lower. } \\
\text { Pupils do not react to light. Muscle tone (except } \\
\text { diaphragmatic) is lost. Animal has no response to } \\
\text { surgical manipulation and all peripheral reflexes } \\
\text { are diminished or absent. }\end{array}$ \\
\hline $\begin{array}{l}\text { Plane IV } \\
\text { Very deep }\end{array}$ & $\begin{array}{l}\text { Pupils do not react to light and stay dilated. MAP } \\
\text { becomes weak, abnormal, and thready. } \\
\text { Respiration is very shallow. Animal initiates } \\
\text { breathing from its abdomen (abdominal } \\
\text { breathing). }\end{array}$ \\
\hline
\end{tabular}

\section{ANESTHESIA MONITORING IN RODENT INVASIVE PROCEDURES}

Rodent monitoring needs to be performed frequently by making diligent notes and records to assess quality of surgical anesthesia, as mentioned in the introduction. Prior to anesthesia, it is also advisable to perform basic behavioral observations from a distance, before transferring rodents out of a vivarium, and later to also carry out a basic triage, please see Table I for values. Moreover, new research into pain monitoring suggests that facial expression can also provide discrete information about rodent clinical status [13], [14]. Basic physiological assessment of peripheral tissue oxygenation/ tissue oxygen saturation, HR, heart rate variability (HRV), body temperature and e.g., BP by a tail cuff method can be performed before e.g., an institution of an invasive BP monitoring, or both methods can be combined later on. Other, less complex monitoring of anesthesia's depth in rodents requires checking the peripheral nociception by using motor-based peripheral reflexes (toe pinch /pedal withdrawal reflex). Toe pinch is an ascending painful stimulus that leads to hypothalamic activation that in turn increases sympathetic-adrenergic system activity leading to a secretion of e.g., noradrenaline, corticoids, glucagon, adrenocorticotrophic hormone (ACTH) and antidiuretic hormone $(\mathrm{ADH})$. The prudence of its frequent testing and retesting is warranted, as it leads to a conditioning response with effects on cardiovascular parameters such as HR, HRV and $\mathrm{BP}$, hence the reflex testing should be limited to a prespecified time-point during the general anesthesia and replaced later by other mode of monitoring or a its combination. If an immediate response on toe pinch is observed, e.g., by changes of pattern of breathing or increase of HR or HRV, the anesthesia and its plane have to be reassessed and noted in the monitoring record. In most cases the righting reflex, abdominal region pinch reflex or pedal withdrawal reflex are surrogates for achieving surgical anesthesia. Peripheral nociception in rodent surgery still has its important place when performing an acute hemodynamic procedure. Assessment of anesthetic depth using reflex responses to a stimulus combined into a score system in mice was recently reviewed by [15].

TABLE II: TRIAGE VALUES FOR MOUSE AND RAT BASED ON [16]. BRACKETED ARE THE MEAN VALUES

\begin{tabular}{|c|c|c|}
\hline Triage value & Mouse & Rat \\
\hline $\begin{array}{c}\text { Rectal temperature } \\
\text { in }{ }^{\circ} \mathrm{C}\end{array}$ & $35.8-37.4(36.6)$ & $35.9-37.5(36.7)$ \\
\hline Breath rate/ min & $90-220(155)$ & $70-115(93)$ \\
\hline Heart rate/ min & $450-780(615)$ & $250-450(350)$ \\
\hline
\end{tabular}

\section{INJECTABLE ANESTHESIA to Assess RodENT HEMODYNAMICS}

As stated earlier, injectable anesthesia is considered less desirable in the assessment of rodent hemodynamics. Injectable anesthesia used in rodents was the most prevalent choice of anesthesia in the past due to lack of access to the inhalation circuitry, suitable mechanical ventilator, or removal of toxic gases. This type of anesthesia is less controllable with slow induction and does not, in many cases, produce a consistent surgical anesthetic depth due to reliance on an individual's genetic makeup. The ability of certain anesthetic agent to induce surgical anesthesia is an important goal, however it is most often their side effects that rule them out from their widespread use in rodents. Additionally, dose of injectables can only be estimated based on body mass and fat composition (or its combination); first can be measured, second can only be estimated. Correspondingly, due to lesser ability to control the plane of anesthesia by using injectables, dynamic monitoring of anesthesia's stage and planes is required. Likewise, it is also important to acknowledge that not all rodents in the animal facility are in top physical shape to be assessed using an invasive procedure. If there is presence of unacceptable body condition score, skin injury, low food and water intake, defecation, urination, nose, or eye gland discharges e.g., chromodacryorrhea, or perineal soiling, it might be very challenging to manage anesthesia or to obtain good hemodynamic data as for the underlined stress. Unless we improve the clinical status of the rodent prior to an invasive catheterization, it might be advisable not to engage into an invasive procedure. Also, at least three days should be allocated for rodent's adaptation post arrival, which might also serve as good time for further clinical examination [17]. In spite of some obvious disadvantages such as difficulty of choosing an initial dose, impracticality of removal dose once injected, and no possibility of accurately regulating the depth of prolonged anesthesia, reversible agents with its high therapeutic index are still an option. In line with standards of 
balanced anesthesia, a combination of injectable agents should be selected to minimize side effects but also the adverse effects, when used simultaneously. In many cases to refine surgical anesthetic protocol suitable for hemodynamic study, pilot experiment is recommended to find correct dose, and to probe for adequacy and duration of anesthesia, anticipating technical and procedural problems. These are equally related to new surgical procedure and or hemodynamic measurement, where familiar anesthetic methods and doses may prove to be inadequate as e.g., higher dose of Propofol or Barbiturates might not induce an additional surgical plane of anesthesia, rather might lead to an increased cardiopulmonary depression. Additionally, most of the injectables are made in higher concentrations, hence frequent dilutions need to be performed for a rodent. When diluted, anesthetics usually run out earlier as to a concentrated stock. It is also advisable to read up on the specific injectable before its dilution as e.g., Diazepam is poorly soluble in water and is usually formulated in propylene glycol; when diluted in saline or water-soluble anesthetics it tends to precipitate. By contrast, midazolam is water soluble [18].

The most widely used injectable anesthetic in rodents, replacing Barbiturates, is Ketamine, used either alone or in its combinations [19]. It produces dissociative type of anesthesia with distortion of sight, distortion from surrounding environment, in conjunction with only shallow sleep facilitated by interruption of neuronal transmission from the unconscious to conscious parts of the brain leading to a prolonged recovery. Ketamine is also known for poor analgesia and poor muscle relaxation, and often increased muscle tone with involuntary movements [18]. In the introduction briefly mentioned anesthetic and analgesic properties of ketamine, which are directly through direct ketamine-induced inhibition of NMDA receptors, however other putative lower-affinity pharmacological targets of ketamine include, but are not limited to, GABA, dopamine, serotonin, sigma, opioid, and cholinergic receptors, as well as voltage-gated sodium and hyperpolarization-activated cyclic nucleotide-gated channels [20], [21]. Ketamine alone does not produce a state of plane of surgical anesthesia, however, is able to increase $\mathrm{BP}, \mathrm{HR}$, and $\mathrm{CO}$ with minimal respiratory depression [22], hence used in humans with combination with midazolam or propofol in intensive care patients during cardiovascular instability [20]. Once Ketamine is injected, animals will initially lose orthostatic reflexes, but without an impairment of consciousness [23], [24], maintaining pharyngeal, laryngeal, corneal, palpebral, and swallowing reflexes. For that reason, Ketamine is generally accompanied by e.g., $\alpha 2$-agonist (Xylazine, Medetomidine and Dexmedetomidine) ensuring proper level of analgesia and sedation. Doses of Ketamine $(80-100 \mathrm{mg} / \mathrm{kg})$ with Xylazine $(5-10 \mathrm{mg} / \mathrm{kg})$ are widely used as i.p. combination, which is safe and reliable for short to moderate surgical anesthesia duration, about $30 \mathrm{~min}$ in a rat [22]. For rodent PV procedures it is only a mediocre type of anesthesia as for resulting hypotension and other negative hemodynamic side effects, such as lowering of the cardiac output [25].

Addition of Dexmedetomidine (Ketamine, $75 \mathrm{mg} / \mathrm{kg}$; Dexmedetomidine $1.0 \mathrm{mg} / \mathrm{kg}$ ) creates negative hemodynamic effects such as hypothermia, respiratory depression, and cardiac output due to bradycardia [26] and (or) they could also increase peripheral vascular resistance [27]. Dexmedetomidine is used in combination with $\mathrm{K}$ to lower $\mathrm{K}$ dose, while attaining comparable levels of anesthesia as with $\mathrm{K} / \mathrm{X}$. Xylazine use is sometimes attributed to polyuria due to its reducing effect on vasopressin's secretion [28]. BP may slightly increase due to vasoconstriction, which is followed by hypotension. In all these cases, researchers need to make detailed notes into a recorded file to capture this hemodynamic effect longitudinally. Xylazine is used in rodents in combination with Ketamine as it secures an analgesia, moreover, it potentiates many general anesthetics [27]. A significant advantage of Xylazine is its ability to be reversed by specific antagonists, including Yohimbine, Tolazoline, Atipamezole [29]. For Atipamezole (0.1-1 $\mathrm{mg} / \mathrm{kg}$, i.p or s.c) and Yohimbine (1-2.1 mg/mg, i.p or s.c ) doses can be used [18]. Actions of Medetomidine and Dexmedetomidine can also be reversed by Atipamezole [30]. Hemodynamics needs to be carefully monitored and recording notes needs to be updated when $\alpha 2$-agonist is reversed. Additionally, please remember, if you reverse the $\alpha 2$-agonist early, Ketamine effects might present itself as an increased muscle tone with an involuntary movement. Besides, Ketamine and other dissociative anesthetics typically cause an initial hyper salivary and bronchial secretion response in rodents. It is best practice to check for an excess of glandular secretion, and if necessary, use anticholinergics. When controlling the hypersalivation, atropine or glycopyrrolate are utilized. Glycopyrrolate was shown to be superior in a rat during maintenance of the HR in Ketamine/ Xylazine or Ketamine/ Dexmedetomidine anesthesia [18]. This may be attributed to a reduced rate of hydrolytic degradation and a higher anticholinergic activity in rats [31]. Effects of all thus far presented injectable anesthetics should be carefully appraised before major loaddependent parameters are compared to TTE, micro-CT or other imaging.

Further lowering dose of Ketamine to $(40-80 \mathrm{mg} / \mathrm{kg}$ ) along with an unchanged dose of Xylazine $(5-10 \mathrm{mg} / \mathrm{kg}$ ) by Acepromazine $(1 \mathrm{mg} / \mathrm{kg})$, used as an i.p. injection, surgical plane of anesthesia in rodents might not be fully achieved to perform rodent intravascular catheterization. Acepromazine in this combination is used to augment muscle relaxation, however in recent study by [32], acepromazine could cause significant decrease of an insulin level in C57BL/6 mice, which was accompanied by an immediate increase in blood glucose, disappearing only after $30 \mathrm{~min}$ of anesthesia. Instead, combination of higher dose of Ketamine $(125 \mathrm{mg} / \mathrm{kg})$ with Medetomidine and Atropine, used in mouse by an i.p injection, offered superior surgical anesthesia with better maintenance of arterial BP, nevertheless at the cost of low HR when compared to volatile anesthesia by isoflurane at maintenance dose of $1.5-2 \%$ [32].

In a rat, combination of Ketamine with benzodiazepines such as Midazolam uses a higher dose of Ketamine (75$100 \mathrm{mg} / \mathrm{kg}$ ). In this combination very good complementary tranquilizer Midazolam is used at doses of $4-5 \mathrm{mg} / \mathrm{kg}$, both injected i.p. This combination has been reported to significantly protect $\mathrm{HR}$ as compared with the Ketamine $(100 \mathrm{mg} / \mathrm{kg})$ and Dexmedetomidine $(0.25 \mathrm{mg} / \mathrm{kg})$, which has achieved greater anesthesia depth when compared to $\mathrm{K}+\mathrm{M}$ treated rats [33]. In the same report authors claim that the 
pedal withdrawal reflex was lost only in rats in the Ketamine/ Dexmedetomidine group, implying that surgical anesthesia was only achieved with these combinations [33]. Midazolam can remove the effect of post-Ketamine seizures and has reasonable effects on hemodynamics, however complete surgical anesthesia (Stage III, Plane III; see Table II) has to be guaranteed prior to an intravascular catheterization. Perhaps more research needs to be done to titrate and adjust the dose of Midazolam. At the moment, use of an $\alpha 2$-agonist could represent a safer alternative.

Combination of Tiletamine and Zolazepam in (Telazol) for rodent surgical anesthesia, with ketamine's dissociative-like effects of Tiletamine and another benzodiazepine tranquilizer Zolazepam, is recommended for rat at dose of $40-50 \mathrm{mg} / \mathrm{kg}$ i.m, with the best cardiovascular effect at dose of $50 \mathrm{mg} / \mathrm{kg}$ [34]. In this combination Zolazepam brings out its tranquilizing effects causing muscle relaxation with ability to protect HR, MAP, and cardiac index [34]. Combination produces adequate plain of surgical anesthesia in rodents in about $108 \mathrm{~min}$ with the $50 \mathrm{mg} / \mathrm{kg}$ dose. Duration of the effect is dose dependent in rats, with corneal, pedal, and swallowing reflexes that might remain intact [34]. When Telazol doses of 40 up to $60 \mathrm{mg} / \mathrm{kg}$ were compared in rat study to barbiturates at 120 min post-injection, breath rate, MAP and cardiac index was protected as compared to Pentobarbital at $45 \mathrm{mg} / \mathrm{kg}$ i.p. Using barbiturates in rats produces hypnotic effects with limited amounts of analgesia, accompanied by narrow safety margins, usually complemented by dose dependent respiratory and cardiovascular depression [18], [22], [35].

Sodium Pentobarbital in a rat is recommended at 30$60 \mathrm{mg} / \mathrm{kg}$ i.p. (Flecknell PA, 2016), and for its mostly hypnotic effect, not in most cases accompanied by pedal withdrawal reflex, is not a preferred choice of anesthesia for an invasive catheterization. Likewise, dose increments (typically a quarter of an original dose) bring more cardio and pulmonary depressant effects with not enough analgesia and rapid body temperature loss, which is less desirable for PV or central pressure interrogations. Both Thiopental and Methohexital produce only an ultrashort surgical anesthesia in a rat, about $10 \mathrm{~min}$, both after i.v. injection with insufficient analgesia [22].

Propofol is widely used as an intravenous hypnotic anesthetic drug, employed for an induction and maintenance of general anesthesia, with its sedative/hypnotic effects that can be titrated into constant intravenous infusion in a rat. In the Propofol monograph compiled by Baxter Corporation, Mississauga $(\mathrm{ON})$, female rats had longer sleeping time as compared to males post single i.v. bolus dose of $15 \mathrm{mg} / \mathrm{kg}$, accompanied by steep dose-response curve and presence of Propofol in the blood after awakening. Propofol in a rat is an underappreciated singular type of anesthesia in cardiovascular research. Cardiovascular side effects of this hypnotic drug are known to be related to the blockage of the voltage-gated sodium $(\mathrm{Na}+)$ and potassium $(\mathrm{K}+)$ channels at the molecular level [36]. It blocks the $(\mathrm{Ca} 2+)$ channels and activates protein kinase $\mathrm{C}$ with increased stimulation of nitric oxide production. This action in rats decreases an overall cardiac preload (LVEDP), preserves ventricular relaxation $(-\mathrm{dP} / \mathrm{dt})$ and protects the left ventricular function, as reflected in a study by [37]. In a rat, the nature of Propofol maintenance and its necessity of constant infusion monitoring, with frequent dose adjustments, limit its use in hemodynamic procedures including PV catheterization. Studies using i.p. dosages of Propofol found that, as monoanesthesia, the most predictable dose was $200 \mathrm{mg} / \mathrm{kg}$ i.p., for which 3 of the 4 rats in the group lost the righting reflex, whereas lower doses failed to induce surgical anesthesia [38]. Moreover, the $25 \mathrm{~min}$ surgical anesthesia window could be achieved comfortably only when medetomidine $(0.1 \mathrm{mg} / \mathrm{kg}$ i.p. $)$, and fentanyl $(0.1 \mathrm{mg} / \mathrm{kg}$ i.p. $)$ were added to $100 \mathrm{mg} / \mathrm{kg}$ of propofol i.p. [38]. In a mouse hemodynamic trial using a combination of Propofol with Fentanyl and Midazolam; induction with 35 $\mathrm{mg} / \mathrm{kg}$ propofol, $1.2 \mathrm{mg} / \mathrm{kg}$ fentanyl, and $20 \mathrm{mg} / \mathrm{kg}$ midazolam as an i.p. bolus of $0.315 \mathrm{~mL} / 10 \mathrm{~g}$; maintenance by continuous i.p. infusion of $90 \mathrm{mg} / \mathrm{kg} / \mathrm{h}$ propofol and 1.6 $\mathrm{mg} / \mathrm{kg} / \mathrm{h}$ fentanyl led to protection of MAP and HR [32].

In the recent randomized crossover study comparing anesthesia during left ventricle assessment by TTE in mice, four anesthetics were compared to a trained fully conscious mouse [8]. Tribromoethanol (Avertin) at a dose of $290 \mathrm{mg} / \mathrm{kg}$ i.p. was able to protect $\mathrm{HR}$ and $\mathrm{EF}$ when compared to Isoflurane or a combination of Ketamine/Xylazine (100 and $10 \mathrm{mg} / \mathrm{kg}$ i.p. [8]. Avertin with its effect belongs to sedatives/ hypnotics, with only limited amount of analgesia, not considered as a good candidate for any invasive assessment of hemodynamics by transit-time blood flowmetry of the ascending aorta in mice as noted by Janssen et al [25].

When clinical drug is being used to keep rodent at required stage III, plane III, detailed notes need to be kept in order to evaluate hemodynamics. This is applicable in case of Urethane (Ethyl Carbamate), still used in labs today to inquire about hemodynamics to compare, or better to avoid known receptor interactions [25], [39]. Urethane was used for a long period of time in human clinical medicine in treatment of multiple myeloma, and then its use was suspended after it was found to be cancerogenic [40]. Urethane is still being used today in rodent-based experimental medicine due to its prolonged anesthetic effect and preservation of arterial BP and $\mathrm{CO}$, when e.g., compared to isoflurane in mouse model [25]. In this study, surgical anesthesia was achieved however only after using very high doses with an initial dose of 1250 $\mathrm{mg} / \mathrm{kg}$, and two supplemental injections of $500 \mathrm{mg} / \mathrm{kg}$ each. [25]. Urethane in hemodynamic study was also used earlier in a murine model by Jong et al, where close to physiologic hemodynamic conditions were essential to be achieved for several hours to study cardiovascular physiology [41]. To that effect, hemodynamic was protected for that period of time, by possibly avoiding certain receptor interactions [39]. Nevertheless, other adverse effects such as severe metabolic acidosis [42] and need of very high dose injections with frequent reinjections to preserve surgical anesthesia, makes urethane less desirable rodent-based anesthetic. Additionally, its combination with $\alpha$-chloralose to secure long lasting light anesthesia was also described as not sufficient to attain surgical type of anesthesia in mice by [32], [41]. 


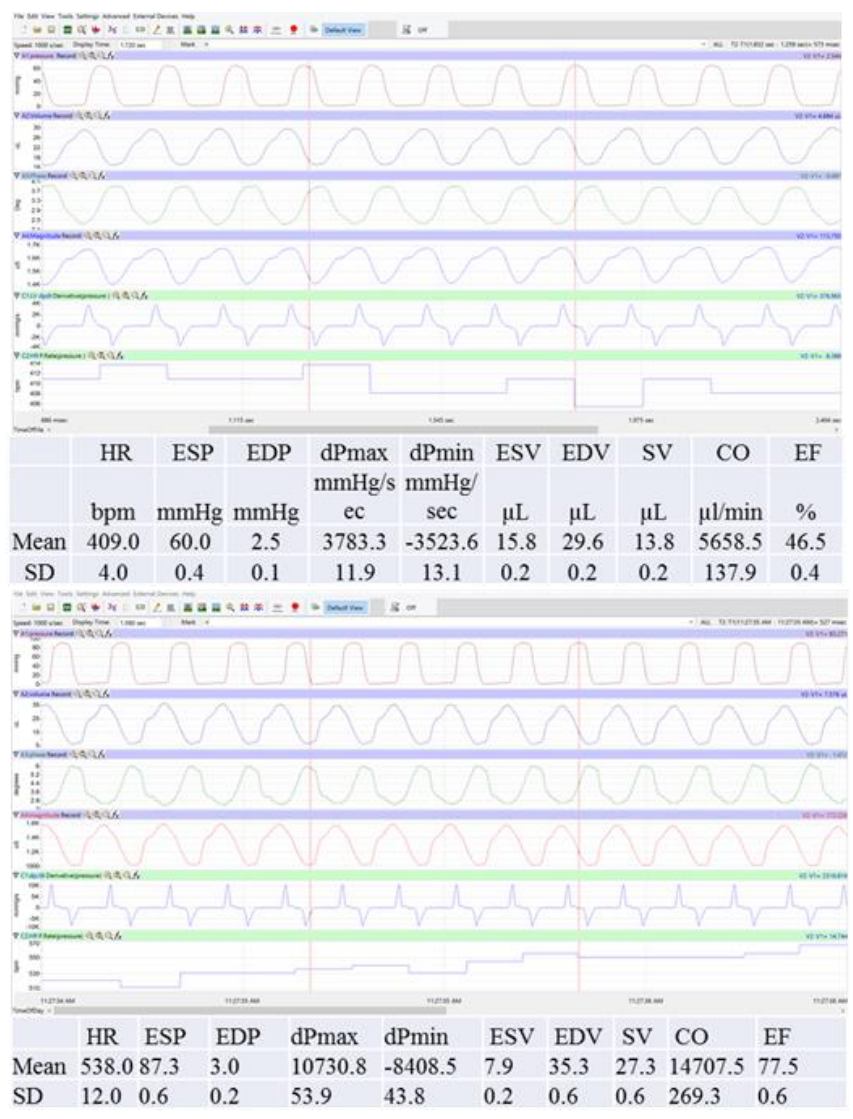

Fig. 2. Comparison of General anesthesia in hemodynamic exam. In the first example (on the top), data were taken from 24.3g male mouse that has been injected with combination of Ketamine/Xylazine (50 and $10 \mathrm{mg} / \mathrm{kg}$ i.p.) and under general anesthesia for $2 \mathrm{~h}$, however re-injected by half dose at $30 \mathrm{~min}$ before taking this recording; mouse was catheterized using the right carotid artery and was breathing room air. Pressure-volume catheter was placed and secured in the LV. Tabulated data are from 10 cardiac cycles (Mean $\pm \mathrm{SD}$ ). Direct comparison of the waveform recordings and tabulated values can be made with waveform recording and table on the bottom. These data are taken from a $27 \mathrm{~g}$ male mouse under general inhalation anesthesia using Isoflurane in $100 \%$ oxygen. In this case, both the induction and anesthesia maintenance are done by Isoflurane. Data are taken $2 \mathrm{~h}$ post induction at $1 \%$ Isoflurane in $100 \%$ oxygen $(\mathrm{v} / \mathrm{v})$ concentration. Mouse was catheterized using the right carotid artery. For comparison, tabulated data are from 10 cardiac cycles (Mean \pm SD). We can observe from 10 cardiac cycles that hemodynamics in the first case, under the $\mathrm{K} / \mathrm{X}$ anesthesia, has been noticeably influenced by the second delivery of a half dose of injectable anesthesia (lower HR and chamber pressures, including dp/dt max and min and all chamber volumes).

Similarly, in the report by Lau et al, not sufficient surgical anesthesia was reported using Alfaxalone. Alfaxalone is neuroactive steroid with hypnotic effect and complex inhibition of neuronal excitability with sex-dependent pharmacokinetics. In a single injection of rat as Alfaxan given i.p., stable levels of alfaxalone were reported, with longer sleep times than i.v. dosing, although immobilization was not induced in $30 \%$ of rats given Alfaxan IP [43]. When administered i.v. and at a constant rate infusion, influence of arterial BP was reported [44]. After discussion of common injectable rodent-specific anesthesia, meant to be used in the invasive hemodynamic exam, we shift our attention to volatile gas anesthesia. In the next section, paragraphs are devoted to delivery of general inhalation anesthesia using non-invasive (NIV) and invasive CMV.

\section{INHALATION GENERAL ANESTHESIA USING VOLATILE GAS DELIVERED THROUGH NON-INVASIVE METHOD}

Inhalant anesthetics (e.g., Isoflurane, Sevoflurane, Desflurane) have a greater margin of safety in rodents as they produce stable plane of surgical anesthesia as compared to most injectable anesthetics, currently used to perform an invasive rodent catheterization, for more information please see volatile anesthetics comparison in Table IV. General anesthesia induced by frequently selected monoanesthesia in rodents using volatile gas to inquire about cardiovascular hemodynamics has also its complexities, some of which are discussed in following paragraphs. Rodent non-invasive ventilation (NIV) in these paragraphs is delivered by using a face mask or nose cone; more about setting up ventilation circuitry is covered in the next section.

The elimination of inhalation anesthetics is typically by lungs, allowing prompt induction and recovery as compared to most injectables such as (Pentobarbital, Thiopental, Ketamine or Tiletamine), where the initial elimination can be slowed down by its organ and tissue redistribution, influenced by tissue metabolism and excretion [45].

The potency of inhaled agents is expressed as minimum alveolar concentration (MAC), the equivalent of the effective dose (ED 50) when a group of animals fails to respond to a standard noxious stimulus $50 \%$ of the time [22]. Recently compared three anesthetic options in hemodynamic rat study (TTE combined with LV pressure catheterization), showed that isoflurane produced equivalent levels of cardiovascular depression (HR, MAP) as Pentobarbital and Ketamine/Xylazine, though significantly more cardiovascular depression than Tiletamine/Zolazepam [35].

Using inhalation anesthesia, especially in the case of Isoflurane, might increase neuroprotection in rats as outlined in the recent review [46]. Currently understood mechanisms of isoflurane actions is to antagonize the NR1 subunit of the $\mathrm{N}$-methyl-D-aspartate (NMDA) glutamate receptor, which blocks its input on synaptic transmission [47], [48]. Using the mouse model, the most appropriate Isoflurane level was identified as $1.5 \%$ v/v, yielding stable MAP and HR values comparable to those observed in the animal's conscious state [49]. Using isoflurane anesthesia, at $150 \mathrm{~min}$ after isoflurane initiation, at $1.5 \%(\mathrm{v} / \mathrm{v})$ concentration to maintain anesthesia, BP and HR were sustained at $71 \%$ and $79 \%$ of their awake levels amid a trend of progressive increase [50]. Furthermore, in rodents baroreflex-mediated sympathetic vasomotor tone has been gradually reversed from an $85 \%$ reduction toward the conscious level. A decline in excitatory connectivity was noted between nucleus tractus solitarius and nucleus ambiguuus, which was accompanied by decrease in cardiac vagal baroreflex [50]. Large functional capacity and plasticity of both baroreflex-preserving cardiovascular functions and its regulations, might be capable of maintaining sufficient circulatory supply of oxygen to brain tissues [50]. In vascular beds of contracting cardiac muscle, Isoflurane action causes potent vasodilation influencing myocardial oxygen consumption. This is a highly debatable topic in the current literature due to systemic hemodynamic changes post Isoflurane inhalation e.g., in case of aortic hypotension that might have profound impact on myocardial oxygen consumption [51]. More imaging research, including pressure and PV sensor detection, needs to be performed post- 
Isoflurane and other inhalational anesthetics, showing how MACs affect coronary vascular beds while influencing myocardial oxygen consumption.

Using an inhalant gas as an induction to surgical anesthesia, followed by its maintenance, needs to be accompanied by the pre-emptive analgesia. When analgesia using opioids Fentanyl or Remifentanil in rats was accompanied by the inhalation gas (having mostly a hypnotic effect), documented MAC decreased in dose dependent fashion [52]. There is an active discussion about the value of analgesia and the decrease of MAC of isoflurane using nonsteroidal anti-inflammatory drugs (NSAID) in rodents. It was documented that in a rat, Aspirin synergistically potentiates MAC of Isoflurane, produced by morphine, as opposed to Meloxicam [53]. In case of Sevoflurane, analgesic additive effect of Remifentanil on MAC of Sevoflurane was observed only in combination with Paracetamol, whereas Metamizole, Ketoprofen, and Parecoxib failed to produce such potentiation [54]. Generally, in cases of volatile inhalation anesthesia, selected opioid analgesics should be introduced before rodent is induced in the inhalation chamber, however, if combined with NSAIDs, the intraoperative rather than preoperative administration of these drugs is suggested as for cyclooxygenase (COX) inhibitors preventing tolerance effect to opioids (Benito J, 2010). Selected NSAIDs in rodents, in many cases, do not interfere with collection of good cardiovascular data. NSAIDs also retain their anti-inflammatory action, predominantly through inhibition of the enzyme COX, inhibiting prostaglandin synthesis [55]. Greater potentiation of presynaptic inhibitory effects of morphine was achieved by the nonselective COX inhibitors over the specific COX-2 inhibitor, which could be indicative of synergistic effects of NSAIDs mediated by inhibition of COX-1 [56]. Their wellknown side effects are (ulceration of the GI tract, impairment of platelet aggregation, nephrotoxicity, bone healing impairment and hepatotoxicity), which are rarely described in the course of its short-term administration, for the purpose of collecting rodent hemodynamics. Currently, only few reports list its hemodynamic side effects due to its chronic overuse, known to induce acute kidney injury and through an interaction with other drugs they may partially inhibit enzyme Cytochrome CYP-2C9. Novel reports also discussed selective actions of COX-2 inhibitors, as they increase the risk of myocardial infarction by specifically inhibiting endothelial COX-2 derived prostacyclin (PGI2) [57]. Opioids are known for its hemodynamic side effects, especially limiting breathing pattern and breathing rhythm generation and when e.g., combined with sevoflurane [54] or midazolam [58], the opioid effects on respiratory depression was found to be enhanced [59].

\section{RODENT VENTILATION CIRCUITRY SET UP TO DELIVER VOLATILE GAS ANESTHESIA}

Common function of all breathing circuits is to distribute mixture of a gas to rodents, while eliminating expired carbon dioxide. When setting up rodent ventilation circuitry the carrier gas oxygen, or an oxygen/nitrous oxide mixture, with a percentage of volatile anesthetic is delivered to the rodent through the breathing circuit. Oxygen can be delivered either by a central wall distribution system or comes from colorcoded pressurized tanks. For more details please see [60]. In rodents, most important breathing circuits that are used are non-rebreathing as compared to rebreathing (typically used in large animals only). In case of rodents, expired $\mathrm{CO}_{2}$ is not removed by vacating the exhaled gases from the system, but by absorbing it using an absorbing compound e.g., soda-lime, activated charcoal etc. The main characteristic of a nonrebreathing system is that there are no gases to be re-inspired or re-breathed, instead gases vacate the system after its first pass. There are multiple possibilities of structuring these circuits and are mostly based on Mapleson's division A-F [6], [61]. One of the Mapleson set up is the D type, also known as Bain circuit, that is frequently used in many laboratories for rodent PV anesthesia [6], [61]. This circuit uses very high fresh gas in-flows that deliver the anesthetic gas and washes out the exhaled $\mathrm{CO}_{2}$. After this first pass of the gas mixture, an exhaust hose scavenges and evacuates an excess of anesthetic gases, avoiding gas recirculation.

It is known that freshly inhaled gas is not pre-warmed and also it is very dry, hence it decreases rodent's body temperature and might irritate airway passages as gases are constantly inhaled. During an acute procedure, such shortcomings might influence final airway pressures and in extension hemodynamic data, however at present signs are underreported as they are very discrete and not readily manifested during the anesthesia. Additionally, benefits of using $100 \%$ oxygen as a carrier gas for an Isoflurane inhalant anesthesia has been questioned in rodents, due to possible alveolar atelectasis [62]. Gas concentration gradient helps to exchange the gases across the respiratory surfaces through the process of diffusion. Diffusion of a gas takes place from a zone in which the gas exerts a high partial pressure to a zone in which it exerts a lower partial pressure and is determined by 2 basic laws (Fick's and Graham's). Factors which influence the diffusion of gases in the lung are multiple and are described in separate monographies [63]. Recently, imaging in humans has confirmed the existence of areas of absorption atelectasis in lungs based upon oxygen concentration [64]. As oxygen is extremely soluble in blood, it quickly diffuses across the alveoli into the bloodstream, accelerating the rate of alveolar collapse [62]. Study has further shown that rats would additionally benefit to have carrier gas oxygen set at $21 \%$ as compared to mice due to larger perturbation in physiological variables and downstream inflammatory effects [62]. Toxic waste generated needs to be safely captured and evacuated from animal OR. In case of rodents, face mask has to be tightly fitted as most rodents are strict nose-breathers due to juxtaposition of epiglottis to the soft palate [65]. Pollution also occurs during rodent's chamber induction, spillage when filling the precision vaporizer, anesthesia maintenance and by a loose-fitting face mask. Volatile pollutants should be safely redirected and filtered and evacuated without returning them into the OR's ventilation system, or a direct connection to the building exhaust system should be designed by an active (i.e., vacuum driven) or passive (activated charcoal canisters). When using an absorbent material, such as activated charcoal as in e.g., the F/Air Canisters, it is good practice to record weight of the F/Air canister upon its installation, as canisters should be replaced after its weight increases by 50 grams 
from its original weight. Alternatively, F/Air canister should be replaced after twelve hours of anesthetic time at an oxygen flow rate of 2 liters/min. It is also good to know that F/Air canisters only absorb halogenated gases, and not e.g., nitrous oxide. The orotracheal intubation and CMV are preferred methods to administer rodent inhalant gases, as it allows fast response to crisis such as hypoventilation, respiratory or cardiovascular arrest during an invasive catheter placement. After an invasive intubation using modified rodent endotracheal (ET) tube, the non-rebreathing ventilation circuitry is connected to rodent mechanical ventilator. Invasive non-surgical placement of an ET tube requires patience and excellent visualization of the trachea. Multiple companies selling an intubation kit to orotracheally intubate both mouse and rat. It usually takes multiple days of practice before the intubation is successful. Moreover, it requires constant repetition to preserve the level of learned knowledge. When errors are made e.g., by introducing ET tube directly into an esophageal orifice, instead of trachea, animal might suffer fulminant gastric distension and needs to be euthanized. Particularly in non-anesthetized rodents, with breath rate that might exceed 100's breaths per min. Testing of the correct placement of ET tube by using a small handheld balloon might improve chance of rodent survival prior to ET tube connection to a breathing circuitry. Additional working knowledge of the equipment on part of veterinary anesthesiologist or surgeon is required to perform an ET tube selection and its application e.g., by confirming ET tube location [66], or later its fit and air leak assessment to minimize death space in trachea [67]. Soon after the ET tube placement, confirmation can be done by simple liquid-based method by [68], or by superior technique using an endoscope [66] or simply by an illumination device [69]. If you are constantly experiencing air/volatile gas leaks, due to not properly sealed the area around trachea, performing surgical tracheostomy to secure ET tube might be required.

TABLE III: CONTROLlED VOLUME VENTILATION SET UP BASED ON ANIMAL'S BODY WEIGHT (MB)

\begin{tabular}{cccccc}
\multicolumn{6}{c}{ ANIMAL's BODY WEIGHT (MB) } \\
$\begin{array}{c}\text { Rat } \\
\text { Mb in Kg }\end{array}$ & Vt (ml) & $\begin{array}{c}\text { VR } \\
(\mathrm{bpm})\end{array}$ & $\begin{array}{c}\text { Mouse } \\
\text { Mb in Kg }\end{array}$ & Vt (ml) & $\begin{array}{c}\text { VR } \\
(\mathrm{bpm})\end{array}$ \\
\hline 0.07 & 0.42 & 107 & 0.015 & 0.09 & 159 \\
0.1 & 0.61 & 97 & 0.02 & 0.12 & 148 \\
0.2 & 1.22 & 81 & 0.025 & 0.15 & 140 \\
0.25 & 1.53 & 77 & 0.027 & 0.16 & 137 \\
0.3 & 1.84 & 73 & 0.029 & 0.17 & 134 \\
0.35 & 2.15 & 70 & 0.032 & 0.19 & 131 \\
0.4 & 2.46 & 68 & 0.035 & 0.21 & 128 \\
0.45 & 2.77 & 66 & 0.037 & 0.22 & 126 \\
0.5 & 3.08 & 64 & 0.04 & 0.24 & 124 \\
0.55 & 3.39 & 62 & 0.043 & 0.26 & 121 \\
0.6 & 3.70 & 61 & 0.045 & 0.27 & 120 \\
\hline
\end{tabular}

In small mammals, similar to human counterparts, CMV is set up based on control of volume or pressure. In rodents this type of anesthesia is considered an advanced type, as a surgeon or/ an anesthesiologist assumes full control of ventilation. In many cases, the user has to learn about a specific setup to understand the ventilator's hardware and specific terminology used by the manufacturer. Similarities in ventilator-based hardware and terminology exist, e.g., when breath is initiated by a rodent (assisted) as opposed to when completed by ventilator (controlled) mode. After an inspiration is initiated, there are two target variables in play to deliver the gas to a rodent. One is based on inflow of volume with its target, second is based on pressure target. The breath delivery is ceased when a target volume has been reached by means of $\mathrm{Vt}$, using a known airflow, delivered for a set time. In volume-controlled modes the flow is constant until $\mathrm{V}_{\mathrm{t}}$ is achieved, resulting in constant pressure generation during the cycle, lowering mean airway pressure. In pressure targeted mode, it is the PIP (peak inspiratory pressure) and the inspiratory time, which guides the delivery. Since the specific pressure needs to be delivered in time, PIP might be lower as compared to volume-controlled mode, however the mean airway pressure is higher. The pressure-mode is usually used in instances of an increased airway resistance. In addition, the inspiration/ expiration (I:E) ratio can be set up using e.g. (\%Insp) setting. The volume of gas/air, which is exchanged in one ventilation cycle, is referred to as $\mathrm{Vt}$, whereas the number of the ventilation cycles taking place within a unit of time is known as ventilation rate (VR) or widely mis-used respiration rate. Note: we should be using non-ventilated animal breath rate, and during inhalation anesthesia ventilation rate instead of commonly used respiration rate, as respiration is not a ventilation, since respiration involves exchanging incoming gases, mainly, oxygen and carbon dioxide. Starting from delivery of $\mathrm{V}_{\mathrm{t}}$ and setting up VR, both parameters are closely related to animal body weight, please see (Table III). Table is calculated for rat (70-700g) and mouse (15-50g), formulas are based on publication [70]. Weight of the rodent needs to be measured for calculating dose Vt and VR. Proper ventilator setting is one of the key aspects of good delivery of inhalation anesthesia. After initial ventilation set up, periodic adjustments are necessary based on clinical signs or postopening of chest cavity e.g. As added control, some investigators use collection of arterial blood gases in rodents to curb an initial respiratory acidosis or alkalosis [71].

Additional ventilation testing, before the animal is part of the ventilation circuitry, can be performed by ventilation species-specific testing balloons. To select a proper rodent-based ventilator, anesthesiologists have to decide about the ventilator's main purpose. It is best to start with questions such as: size(s) of rodent(s), benefit to have volume controlled, pressure-controlled or both, would it be important to have an airway pressure monitoring detection to recognize over/under pressurization, or would I need an assist mode to help to wean the animal from the ventilator, or would I benefit to have an adjustable I:E ratio, and lastly, could I ventilate with a medical air or non-flammable anesthetic gases? Various manufacturers of rodent mechanical ventilators outline application-based ventilators in their yearly updated monographies, discussing these features prior to making the final decision.

Large body of knowledge has been gathered in respect to using different controlled modes of ventilation and its effect on hemodynamics in human medicine. There are multiple excellent publications covering this topic [72], [73]. Basic technical knowledge is translatable when performing assisted mechanical ventilation in rodents. Assessment of cardiovascular hemodynamics during ventilation can be very complex, as lungs and heart share common intrathoracic space. Consequently, intrathoracic pressure and also volume 
changes during the respiratory cycle affect the performance of the heart while influencing hemodynamics on a beat-tobeat basis [74].

TABLE IV: Mouse (M) AND RAT (R) Volatile GENERAL ANESTHETICS SUITABLE TO USE IN HEMODYNAMIC STUDIES

\begin{tabular}{|c|c|c|c|c|}
\hline $\begin{array}{c}\text { Volatile } \\
\text { Anesthetic } \\
\text { Agent }\end{array}$ & & $\begin{array}{l}\text { Dose for induction and } \\
\text { maintenance }\end{array}$ & $\begin{array}{c}\text { Comments \& } \\
\text { Volatile agent } \\
\text { comparison }\end{array}$ & $\begin{array}{c}\text { Observed } \\
\text { hemodynamic } \\
\text { adverse } \\
\text { effects }\end{array}$ \\
\hline \multirow[t]{2}{*}{ Isoflurane } & M & $\begin{array}{c}2-4 \% \text { induction } \\
1.5-2 \% \text { maintenance }\end{array}$ & $\begin{array}{c}\text { Gradually } \\
\text { reduces HR } \\
\text { and dynamic } \\
\text { arterial } \\
\text { pressure } \\
\text { magnitude and } \\
\text { increases } \\
\text { HRV in Rat } \\
\text { [75] }\end{array}$ & $\begin{array}{c}\text { Induces } \\
\text { coronary and } \\
\text { peripheral } \\
\text { vasodilation } \\
\text { in mouse [49] }\end{array}$ \\
\hline & $\mathrm{R}$ & $\begin{array}{c}5 \% \text { induction } \\
1.4 \% \text { or } 2 \% \\
\text { maintenance }\end{array}$ & & \\
\hline \multirow[t]{2}{*}{ Sevoflurane } & M & $\begin{array}{c}8 \% \text { induction } \\
2-4 \% \text { maintenance }\end{array}$ & $\begin{array}{c}\text { Compared } \\
\text { with neonates, } \\
\text { the advantage } \\
\text { of sevoflurane } \\
\text { over } \\
\text { isoflurane } \\
\text { appears to be } \\
\text { diminished in } \\
\text { mature rats } \\
\text { [76] }\end{array}$ & $\begin{array}{l}\text { The most } \\
\text { prominent } \\
\text { side-effect } \\
\text { during } \\
\text { anesthesia is } \\
\text { respiratory } \\
\text { depression } \\
\text { with } \\
\text { hypercapnia, } \\
\text { acidosis, and } \\
\text { a marked } \\
\text { decrease in } \\
\text { respiration } \\
\text { rate [77] }\end{array}$ \\
\hline & $\mathrm{R}$ & $\begin{array}{c}8 \% \text { induction } \\
4.1 \% \text { maintenance }\end{array}$ & & \\
\hline \multirow[t]{2}{*}{ Desflurane } & M & $\begin{array}{c}7.5 \% \text { desflurane in } \\
100 \% \mathrm{O} 2 \\
\text { induction } 7.5 \% \\
\text { desfluranemaintenance }\end{array}$ & $\begin{array}{c}\text { Rapid loss of } \\
\text { consciousness, } \\
\text { as reflected by } \\
\text { a blood-gas } \\
\text { solubility } \\
\text { coefficient } \\
\text { approximately } \\
\text { 30-60\% lower } \\
\text { than that of } \\
\text { sevoflurane } \\
\text { and isoflurane } \\
\text { [78] }\end{array}$ & $\begin{array}{c}\text { In rats } \\
\text { decrease in } \\
\text { arterial partial } \\
\text { pressure of } \\
\text { oxygen and in } \\
\text { mean arterial } \\
\text { pressure } \\
\text { during the } \\
\text { time of } \\
\text { anesthesia. } \\
\text { High dose } \\
\text { desflurane } \\
\text { induces } \\
\text { significant } \\
\text { hypotension } \\
\text { [79] }\end{array}$ \\
\hline & $\mathrm{R}$ & $\begin{array}{l}5.7 \% \text { induction } 8.6 \\
\text { and } 5.7 \% \text { maintenance }\end{array}$ & & \\
\hline
\end{tabular}

\section{REFERENCES}

[1] Sonner, J. M., Antognini, J. F., Dutton, R. C., Flood, P., Gray, A. T., Harris, R. A., Homanics, G. E., Kendig, J., Orser, B., Raines, D. E. Rampil, I. J., Trudell, J., Vissel, B., \& Eger, E. I., 2nd (2003). Inhaled anesthetics and immobility: mechanisms, mysteries, and minimum alveolar anesthetic concentration. Anesthesia and analgesia, 97(3), 718-740.

[2] Eger, E. I., 2nd, Tang, M., Liao, M., Laster, M. J., Solt, K., Flood, P., Jenkins, A., Raines, D., Hendrickx, J. F., Shafer, S. L., Yasumasa, T., \& Sonner, J. M. (2008). Inhaled anesthetics do not combine to produce synergistic effects regarding minimum alveolar anesthetic concentration in rats. Anesthesia and analgesia, 107(2), 479-485.

[3] Urban BW, The Site of Anesthetic Action. Schwilden, H., \& Schüttler, J. (2008). Target controlled anaesthetic drug dosing. Handbook of Experimental pharmacology, (182), 425-450.

[4] Olsen R.W, DeLorey T.M. GABA Receptor Physiology and Pharmacology In: Siegel GJ, Agranoff BW, Albers RW, et al., editors. Basic Neurochemistry: Molecular, Cellular and Medical Aspects. 6th edition. Philadelphia: Lippincott-Raven; 1999.

[5] Jevtović-Todorović, V., Todorović, S. M., Mennerick, S., Powell, S., Dikranian, K., Benshoff, N., Zorumski, C. F., \& Olney, J. W. (1998)
Nitrous oxide (laughing gas) is an NMDA antagonist, neuroprotectant and neurotoxin. Nature medicine, 4(4), 460-463.

[6] Mosley CA. Veterinary Anesthesia and Analgesia: in The Fifth Edition of Lumb and Jones. Edited by Kurt A. Grimm, Leigh A. Lamont, William J. Tranquilli, Stephen A. Greene and Sheilah A. Robertson. 2015 John Wiley \& Sons, Inc. Published 2015 by John Wiley \& Sons, Inc.

[7] Rottman, J. N., Ni, G., \& Brown, M. (2007). Echocardiographic evaluation of ventricular function in mice. Echocardiography (Mount Kisco, N.Y.), 24(1), 83-89.

[8] Pachon, R. E., Scharf, B. A., Vatner, D. E., \& Vatner, S. F. (2015) Best anesthetics for assessing left ventricular systolic function by echocardiography in mice. American journal of physiology. Heart and circulatory physiology, 308(12), H1525-H1529.

[9] Liu, X., Rabin, P. L., Yuan, Y., Kumar, A., Vasallo, P., 3rd, Wong, J., Mitscher, G. A., Everett, T. H., 4th, \& Chen, P. S. (2019). Effects of anesthetic and sedative agents on sympathetic nerve activity. Heart rhythm, 16(12), 1875-1882.

[10] Aono, H., Hirakawa, M., Unruh, G. K., Kindscher, J. D., \& Goto, H. (2001). Anesthetic induction agents, sympathetic nerve activity and baroreflex sensitivity: a study in rabbits comparing thiopental, propofol and etomidate. Acta medica Okayama, 55(4), 197-203.

[11] Guedel A.E. Inhalation anesthesia, Ed 2, New York, 1951, Macmillan

[12] Bhargava, A. K., Setlur, R., \& Sreevastava, D. (2004). Correlation of bispectral index and Guedel's stages of ether anesthesia. Anesthesia and analgesia, 98(1).

[13] Sotocinal, S. G., Sorge, R. E., Zaloum, A., Tuttle, A. H., Martin, L. J., Wieskopf, J. S., Mapplebeck, J. C., Wei, P., Zhan, S., Zhang, S., McDougall, J. J., King, O. D., \& Mogil, J. S. (2011). The Rat Grimace Scale: a partially automated method for quantifying pain in the laboratory rat via facial expressions. Molecular pain, 7, 55.

[14] Matsumiya LC, Sorge RE, Sotocinal SG, et al. Using the Mouse Grimace Scale to reevaluate the efficacy of postoperative analgesics in laboratory mice. J Am Assoc Lab Anim Sci. 2012;51(1):42-49.

[15] Kawai, S., Takagi, Y., Kaneko, S., \& Kurosawa, T. (2011). Effect of three types of mixed anesthetic agents alternate to ketamine in mice. Experimental animals, 60(5), 481-487.

[16] Crisler R., Johnston N.A, Sivula C., Budelsky CL; Chapter 4, Functional Anatomy and Physiology in The Laboratory Rat, Mark A Suckow, ed., November 2019. pg.: 1180. Academic Press ISBN: 9780128143384.

[17] Landi, M. S., Kreider, J. W., Lang, C. M., \& Bullock, L. P. (1982). Effects of shipping on the immune function in mice. American journal of veterinary research, 43(9), 1654-1657.

[18] Lofgren J.L.S, Foley P.L., Golledge H.D.R. Anesthesia, Analgesia, and Euthanasia. The Laboratory Rat. 2020:699-745. Editors: Suckow M, Hankenson FC, Wilson R, Foley P. Epub 2019 Nov 15.

[19] Stokes, E. L., Flecknell, P. A., \& Richardson, C. A. (2009). Reported analgesic and anaesthetic administration to rodents undergoing experimental surgical procedures. Laboratory animals, 43(2), 149154.

[20] Sinner B., Graf B.M. Ketamine. in Handb Exp Pharmacol. 2008;(182):313-33.

[21] Zanos, P., Moaddel, R., Morris, P. J., Riggs, L. M., Highland, J. N., Georgiou, P., Pereira, E., Albuquerque, E. X., Thomas, C. J., Zarate, C. A., Jr, \& Gould, T. D. (2018). Ketamine and Ketamine Metabolite Pharmacology: Insights into Therapeutic Mechanisms. Pharmacological reviews, 70(3), 621-660.

[22] Flecknell, P.A. Laboratory Animal Anaesthesia, 4 ed. Academic Press, Oxford, 2016.

[23] Annetta, M. G., Iemma, D., Garisto, C., Tafani, C., \& Proietti, R (2005). Ketamine: new indications for an old drug. Current drug targets, 6(7), 789-794.

[24] Kurdi, M. S., Theerth, K. A., \& Deva, R. S. (2014). Ketamine: Current applications in anesthesia, pain, and critical care. Anesthesia, essays and research, 8(3), 283-290.

[25] Janssen, B. J., De Celle, T., Debets, J. J., Brouns, A. E., Callahan, M F., \& Smith, T. L. (2004). Effects of anesthetics on systemic hemodynamics in mice. American journal of physiology. Heart and circulatory physiology, 287(4), H1618-H1624.

[26] Wellington, D., Mikaelian, I., \& Singer, L. (2013). Comparison of ketamine-xylazine and ketamine-dexmedetomidine anesthesia and intraperitoneal tolerance in rats. Journal of the American Association for Laboratory Animal Science : JAALAS, 52(4), 481-487.

[27] Gaertner D.J., Hallman T.M., Hankenson F.C., Batchelder M.A. Anesthesia and Analgesia for Laboratory Rodents in: Fish R.E., Brown M.J., Danneman P.J., Karas A.Z., editors. Anesthesia and Analgesia in Laboratory Animals, 2nd Edition London: Academic Press, Elsevier; 2008. p. 239-98 
[28] Cabral, A. D., Kapusta, D. R., Kenigs, V. A., \& Varner, K. J. (1998) Central alpha2-receptor mechanisms contribute to enhanced renal responses during ketamine-xylazine anesthesia. The American journal of physiology, 275(6), R1867-R1874.

[29] Wixson S.K., Smiler K.L., Chapter 9, Anesthesia and Analgesia in Rodents, Editor(s): Dennis F. Kohn, Sally K. Wixson, William J. White, G. John Benson: in American College of Laboratory Anima Medicine, Anesthesia and Analgesia in Laboratory Animals, Academic Press, 1997, p. 165-203.

[30] Kanda, T., Gotoh, M., Makino, A., Furumoto, K., Shimizu, Y., Itoi, T., Maeta, N., \& Furukawa, T. (2020). Effect of Different Doses of Atipamezole on Reversal of Medetomidine-Induced Tear-Flow Decrease in Rats. Veterinary sciences, 7(4), 197.

[31] Olson, M. E., Vizzutti, D., Morck, D. W., \& Cox, A. K. (1994). The parasympatholytic effects of atropine sulfate and glycopyrrolate in rats and rabbits. Canadian journal of veterinary research $=$ Revue canadienne de recherche veterinaire, 58(4), 254-258.

[32] Zuurbier, C. J., Koeman, A., Houten, S. M., Hollmann, M. W., \& Florijn, W. J. (2014). Optimizing anesthetic regimen for surgery in mice through minimization of hemodynamic, metabolic, and inflammatory perturbations. Experimental biology and medicine (Maywood, N.J.), 239(6), 737-746.

[33] Magalhães, A., Valentim, A., Venâncio, C., Pereira, M., Melo, P., Summavielle, T., \& Antunes, L. (2017). Ketamine alone or combined with midazolam or dexmedetomidine does not affect anxiety-like behaviours and memory in adult Wistar rats. Laboratory animals, 51(2), 147-159.

[34] Saha, D. C., Saha, A. C., Malik, G., Astiz, M. E., \& Rackow, E. C. (2007). Comparison of cardiovascular effects of tiletamine-zolazepam, pentobarbital, and ketamine-xylazine in male rats. Journal of the American Association for Laboratory Animal Science : JAALAS, 46(2), 74-80.

[35] Redfors, B., Shao, Y., \& Omerovic, E. (2014). Influence of anesthetic agent, depth of anesthesia and body temperature on cardiovascular functional parameters in the rat. Laboratory animals, 48(1), 6-14.

[36] Stoetzer, C., Reuter, S., Doll, T., Foadi, N., Wegner, F., \& Leffler, A. (2016). Inhibition of the cardiac $\mathrm{Na}^{+}$channel $\alpha$-subunit Nav1.5 by propofol and dexmedetomidine. Naunyn-Schmiedeberg's archives of pharmacology, 389(3), 315-325.

[37] Jin, Y. C., Kim, W., Ha, Y. M., Shin, I. W., Sohn, J. T., Kim, H. J., Seo, H. G., Lee, J. H., \& Chang, K. C. (2009). Propofol limits rat myocardial ischemia and reperfusion injury with an associated reduction in apoptotic cell death in vivo. Vascular pharmacology, 50(1-2), 71-77.

[38] Alves, H. N., da Silva, A. L., Olsson, I. A., Orden, J. M., \& Antunes, L. M. (2010). Anesthesia with intraperitoneal propofol, medetomidine, and fentanyl in rats. Journal of the American Association for Laboratory Animal Science : JAALAS, 49(4), 454-459.

[39] Paasonen, J., Salo, R. A., Shatillo, A., Forsberg, M. M., Närväinen, J., Huttunen, J. K., \& Gröhn, O. (2016). Comparison of seven different anesthesia protocols for nicotine pharmacologic magnetic resonance imaging in rat. European neuropsychopharmacology : the journal of the European College of Neuropsychopharmacology, 26(3), 518-531.

[40] Holland JR, Hosley H, Scharlau C, Carbone PP, Frei E 3rd, Brindley CO, Hall TC, Shnider BI, Gold GL, Lasagna L, Owens AH Jr, Miller SP. A controlled trial of urethane treatment in multiple myeloma. Blood. 1966 Mar.

[41] Jong, W. M., Zuurbier, C. J., De Winter, R. J., Van Den Heuvel, D. A., Reitsma, P. H., Ten Cate, H., \& Ince, C. (2002). Fentanyl-fluanisonemidazolam combination results in more stable hemodynamics than does urethane alpha-chloralose and 2,2,2-tribromoethanol in mice. Contemporary topics in laboratory animal science, 41(3), 2832.

[42] Zehendner, C. M., Luhmann, H. J., \& Yang, J. W. (2013). A simple and novel method to monitor breathing and heart rate in awake and urethane-anesthetized newborn rodents. PloS one, 8(5), e62628.

[43] Lau, C., Ranasinghe, M. G., Shiels, I., Keates, H., Pasloske, K., \& Bellingham, M. C. (2013). Plasma pharmacokinetics of alfaxalone after a single intraperitoneal or intravenous injection of Alfaxan(®) in rats Journal of veterinary pharmacology and therapeutics, 36(5), 516-520.

[44] White, K. L., Paine, S., \& Harris, J. (2017). A clinical evaluation of the pharmacokinetics and pharmacodynamics of intravenous alfaxalone in cyclodextrin in male and female rats following a loading dose and constant rate infusion. Veterinary anaesthesia and analgesia, 44(4), $865-875$.

[45] Jong, W. M., Zuurbier, C. J., De Winter, R. J., Van Den Heuvel, D. A. Reitsma, P. H., Ten Cate, H., \& Ince, C. (2002). Fentanyl-fluanisonemidazolam combination results in more stable hemodynamics than does urethane alpha-chloralose and 2,2,2-tribromoethanol in mice. Contemporary topics in laboratory animal science, 41(3), 2832.
[46] Kitano, H., Kirsch, J. R., Hurn, P. D., \& Murphy, S. J. (2007) Inhalational anesthetics as neuroprotectants or chemical preconditioning agents in ischemic brain. Journal of cerebral blood flow and metabolism : official journal of the International Society of Cerebral Blood Flow and Metabolism, 27(6), 1108-1128.

[47] Yamakura, T., \& Harris, R. A. (2000). Effects of gaseous anesthetics nitrous oxide and xenon on ligand-gated ion channels. Comparison with isoflurane and ethanol. Anesthesiology, 93(4), 1095-1101.

[48] Mawhinney, L. J., de Rivero Vaccari, J. P., Alonso, O. F., Jimenez, C. A., Furones, C., Moreno, W. J., Lewis, M. C., Dietrich, W. D., \& Bramlett, H. M. (2012). Isoflurane/nitrous oxide anesthesia induces increases in NMDA receptor subunit NR2B protein expression in the aged rat brain. Brain research, 1431, 23-34.

[49] Constantinides, C., Mean, R., \& Janssen, B. J. (2011). Effects of isoflurane anesthesia on the cardiovascular function of the C57BL/6 mouse. ILAR journal, 52(3), e21-e31.

[50] Poon, Y. Y., Tsai, C. Y., Huang, Y. H., Wu, J., Chan, S., \& Chan, J. (2021). Disproportional cardiovascular depressive effects of isoflurane: Serendipitous findings from a comprehensive re-visit in mice. Lab animal, 50(1), 26-31.

[51] Feigl E. O. (1983). Coronary physiology. Physiological reviews, 63(1), 1-205.

[52] Criado, A. B., \& Gómez e Segura, I. A. (2003). Reduction of isoflurane MAC by fentanyl or remifentanil in rats. Veterinary anaesthesia and analgesia, 30(4), 250-256.

[53] Santos, M., Kunkar, V., García-Iturralde, P., \& Tendillo, F. J. (2004). Meloxicam, a specific COX-2 inhibitor, does not enhance the isoflurane minimum alveolar concentration reduction produced by morphine in the rat. Anesthesia and analgesia, 98(2).

[54] Benito, J., Aguado, D., Abreu, M. B., García-Fernández, J., \& Gómez de Segura, I. A. (2010). Remifentanil and cyclooxygenase inhibitors interactions in the minimum alveolar concentration of sevoflurane in the rat. British journal of anaesthesia, 105(6), 810-817.

[55] Samad, T. A., Sapirstein, A., \& Woolf, C. J. (2002). Prostanoids and pain: unraveling mechanisms and revealing therapeutic targets. Trends in molecular medicine, 8(8), 390-396.

[56] Vaughan C. W. (1998). Enhancement of opioid inhibition of GABAergic synaptic transmission by cyclo-oxygenase inhibitors in rat periaqueductal grey neurones. British journal of pharmacology, 123(8), 1479-1481.

[57] Das U. N. (2005). Can COX-2 inhibitor-induced increase in cardiovascular disease risk be modified by essential fatty acids?. The Journal of the Association of Physicians of India, 53, 623-627.

[58] Gueye, P. N., Borron, S. W., Risède, P., Monier, C., Buneaux, F., Debray, M., \& Baud, F. J. (2002). Buprenorphine and midazolam act in combination to depress respiration in rats. Toxicological sciences : an official journal of the Society of Toxicology, 65(1), 107-114.

[59] Pattinson, K. T., Governo, R. J., MacIntosh, B. J., Russell, E. C., Corfield, D. R., Tracey, I., \& Wise, R. G. (2009). Opioids depress cortical centers responsible for the volitional control of respiration. The Journal of neuroscience : the official journal of the Society for Neuroscience, 29(25), 8177-8186.

[60] Hall L.W., Clarke, K.W., Trim C.M. Veterinary anaesthesia, 10th ed London; New York : W.B. Saunders, 2001.

[61] Kaul, T. K., \& Mittal, G. (2013). Mapleson's Breathing Systems. Indian journal of anaesthesia, 57(5), 507-515

[62] Wilding, L. A., Hampel, J. A., Khoury, B. M., Kang, S., MachadoAranda, D., Raghavendran, K., \& Nemzek, J. A. (2017). Benefits of $21 \%$ Oxygen Compared with $100 \%$ Oxygen for Delivery of Isoflurane to Mice (Mus musculus) and Rats (Rattus norvegicus). Journal of the American Association for Laboratory Animal Science : JAALAS, 56(2), 148-154.

[63] Petersson, J., \& Glenny, R. W. (2014). Gas exchange and ventilationperfusion relationships in the lung. The European respiratory journal, 44(4), 1023-1041.

[64] Edmark, L., Auner, U., Enlund, M., Ostberg, E., \& Hedenstierna, G (2011). Oxygen concentration and characteristics of progressive atelectasis formation during anaesthesia. Acta anaesthesiologica Scandinavica, 55(1), 75-81.

[65] Harkema J.R.., Carey S.A., Wagner J.G., Dintzis S.M., Liggitt D. 2018. Nose, sinus, pharynx, and larynx. In: Treuting, P.M., Dintzis, S.M., Montine, K.S. (Eds.), Comparative Anatomy and Histology: A Mouse, Rat, and Human Atlas, second ed. Academic Press, London, pp. 89 e 114

[66] Konno, K., Itano, N., Ogawa, T., Hatakeyama, M., Shioya, K., \& Kasai, N. (2014). New visible endotracheal intubation method using the endoscope system for mice inhalational anesthesia. The Journal of veterinary medical science, 76(6), 863-868.

[67] Fox, M. S., Welch, I., Hobson, D., \& Santyr, G. E. (2012). A novel intubation technique for minimally invasive longitudinal studies of rat 
lungs using hyperpolarized $3 \mathrm{He}$ magnetic resonance imaging. Laboratory animals, 46(4), 311-317.

[68] Watanabe, A., Hashimoto, Y., Ochiai, E., Sato, A., \& Kamei, K. (2009). A simple method for confirming correct endotracheal intubation in mice. Laboratory animals, 43(4), 399-401.

[69] MacDonald, K. D., Chang, H. Y., \& Mitzner, W. (2009). An improved simple method of mouse lung intubation. Journal of applied physiology (Bethesda, Md. : 1985), 106(3), 984-987.

[70] Tarnavski, O., McMullen, J. R., Schinke, M., Nie, Q., Kong, S., \& Izumo, S. (2004). Mouse cardiac surgery: comprehensive techniques for the generation of mouse models of human diseases and their application for genomic studies. Physiological genomics, 16(3), 349360 .

[71] Loeven, A. M., Receno, C. N., Cunningham, C. M., \& DeRuisseau, L. R. (2018). Arterial blood sampling in male CD-1 and C57BL/6J mice with $1 \%$ isoflurane is similar to awake mice. Journal of applied physiology (Bethesda, Md. : 1985), 125(6), 1749-1759.

[72] Güldner, A., Kiss, T., Serpa Neto, A., Hemmes, S. N., Canet, J., Spieth, P. M., Rocco, P. R., Schultz, M. J., Pelosi, P., \& Gama de Abreu, M. (2015). Intraoperative protective mechanical ventilation for prevention of postoperative pulmonary complications: a comprehensive review of the role of tidal volume, positive end-expiratory pressure, and lung recruitment maneuvers. Anesthesiology, 123(3), 692-713.

[73] Vieillard-Baron, A., Matthay, M., Teboul, J. L., Bein, T., Schultz, M., Magder, S., \& Marini, J. J. (2016). Experts' opinion on management of hemodynamics in ARDS patients: focus on the effects of mechanical ventilation. Intensive care medicine, 42(5), 739-749.

[74] Konecny, F. (2018) Right ventricular hemodynamics during controlled mechanical volume ventilation as compared to non-invasive ventilation. J Heart Res. 1(1):6-13.

[75] Ghali, G. Z., \& Ghali, M. (2021). Effects of isoflurane on arterial blood pressure, heart rate, and phrenic nerve discharge in the decerebrate rat. The International journal of neuroscience, 131(5), 489-503.

[76] Tsukamoto, A., Niino, N., Sakamoto, M., Ohtani, R., \& Inomata, T. (2018). The validity of anesthetic protocols for the surgical procedure of castration in rats. Experimental animals, 67(3), 329-336.

[77] Cesarovic, N., Nicholls, F., Rettich, A., Kronen, P., Hässig, M., Jirkof, P., \& Arras, M. (2010). Isoflurane and sevoflurane provide equally effective anaesthesia in laboratory mice. Laboratory animals, 44(4), 329-336.

[78] Frost, K., Shah, M., Leung, V., \& Pang, D. (2020). Aversion to Desflurane and Isoflurane in Sprague-Dawley Rats (Rattus Norvegicus). Animals : an open access journal from MDPI, 10(6), 950

[79] Lee, J. H., Kwon, O., \& Kwon, J. Y. (2009). The effects of desflurane on delayed neuronal injury after transient forebrain ischemia in the rat. Korean journal of anesthesiology, 57(2), 195-202.

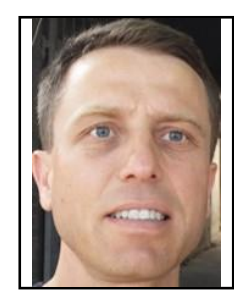

Filip Konecny was born in Czech Republic in 1976. He received the master's and D.V.M. degree in 2000, from the University of Veterinary and Pharmaceutical Sciences, Brno, Czech Republic. $\mathrm{He}$ finished his doctoral studies at 2011 and received $\mathrm{Ph} . \mathrm{D}$. from combined program between McMaster University, Ontario, Canada and the University of Veterinary and Pharmaceutical Sciences, Czech Republic. His post-graduate research at University of Toronto focused on experimental surgery, characterizing rodent protein therapy postmyocardial infarct, and creating mostly rodent cardiovascular models. Later, he concentrated on assessment of ventricular function using both, invasive and non-invasive methods to evaluate ventricular pressure, pressure-volume, transthoracic echocardiography, and other imaging methods.

He is currently Application Scientist and Surgical trainer at Transonic System Inc. and have some teaching duties at McMaster University, Hamilton, ON, where he focuses of lecturing surgery. His recent research efforts focus of heart failure modeling in large animals while combining acute ventricular catheterization with noninvasive imaging. Recently, his emphasis has been on left-ventricle assisted devices (LVADs) helping with characterization of biventricular ( $\mathrm{RV}$ and $\mathrm{LV}$ ) pressure-volume during mechanical cardiac support to characterize the influence of LVADs on beat-to-beat central and peripheral hemodynamics.

Dr. Konecny is member of European Heart Failure Association of ESC, member of (EAPCI, EACVI, EAPC and Czech Cardiovascular Society). 